Case Report

\title{
Nonsuppressible Oral Dexamethasone Suppression Tests but Not Cushing Syndrome
}

\author{
Abilash Nair, ${ }^{1}$ Atul Dhingra, ${ }^{1}$ Anjana Gopi, ${ }^{2}$ and Viveka P. Jyotsna ${ }^{1}$ \\ ${ }^{1}$ Department of Endocrinology and Metabolism, All India Institute of Medical Sciences, New Delhi 110029, India \\ ${ }^{2}$ Department of Pediatrics, ESIC Model \& Super Specialty Hospital, Asramam, Kollam, Kerala 691002, India \\ Correspondence should be addressed to Viveka P. Jyotsna; vivekapjyotsna@gmail.com
}

Received 25 September 2015; Revised 27 February 2016; Accepted 8 March 2016

Academic Editor: Eli Hershkovitz

Copyright (C) 2016 Abilash Nair et al. This is an open access article distributed under the Creative Commons Attribution License, which permits unrestricted use, distribution, and reproduction in any medium, provided the original work is properly cited.

\begin{abstract}
In spite of the presence of definitive diagnostic criteria to diagnose Cushing syndrome diagnosis may become challenging. We report a young female with mild clinical features of Cushing syndrome, who had nonsuppressible oral dexamethasone suppression tests; also she had a suspicious pituitary lesion. She underwent pituitary surgery and a pituitary microadenoma (non-ACTH staining) was removed. Now she had come to us with similar complaints to those before. Again she had nonsuppressible oral dexamethasone suppression tests. As the diurnal variation of serum and salivary cortisol was maintained and urinary free cortisol was normal, further evaluation with IV dexamethasone suppression test was performed which clearly ruled out Cushing syndrome. The patient was not on any medicines known to alter dexamethasone metabolism. Fat malabsorption was also ruled out using appropriate tests. The reason for this discrepancy is thought to be altered (increased) metabolism of dexamethasone in this patient as it is widely variable in the general population.
\end{abstract}

\section{Introduction}

There are definite criteria for diagnosis of Cushing syndrome. Still, in patients with suggestive symptoms and borderline elevations of serum cortisol the diagnosis becomes challenging. In such instances specialized investigations to avoid unnecessary surgery and morbidity may be required.

\section{Case History}

We report a case of a twenty-five-year-old female who initially presented to an endocrinology center at the age of 16 yrs with history of weight gain of $10 \mathrm{~kg}$ over 3 years, mild proximal muscle weakness, irregular menstrual cycles (polymenorrhoea), and intermittent right sided headache. The patient was not on any herbal or naturopathic treatment and was not taking oral contraceptives or any other medicines. The investigations showed unsuppressed overnight and low dose $48 \mathrm{hr}$ dexamethasone suppression test (Table 1 ) and $24 \mathrm{~h}$ urinary free cortisol was not measured. Also MRI sella showed a right sided pituitary microadenoma of size $5 \mathrm{~mm} \times 5 \mathrm{~mm}$.
She underwent transsphenoidal removal of the suspected adenoma at $17 \mathrm{yrs}$ of age with postoperative CSF rhinorrhea for four months. The histopathology showed a pituitary adenoma but no ACTH staining areas. She did not experience a gross difference in her symptoms after the surgery.

After the surgery the patient was started on steroid replacement and referred to our clinic for monitoring of therapy. Prednisolone was used for supplementation in a dose ranging from 10 to $2.5 \mathrm{mg} /$ day. She had hypocortisolemic symptoms on tapering steroid supplementation and required supplementation for 7 years although no stimulation test is available to confirm hypothalamic-pituitary-adrenal axis hypofunction. Thyroid and gonadal axis were preserved. The irregularity of menstrual cycles continued. Steroid supplementation was carefully withdrawn 2 years prior to current investigations. Six months back she complained of recurrence of headache. She had also gained 4-5 kgs of weight over 3-4 months. There were no other symptoms suggestive of recurrence of Cushing syndrome. Physical examination showed no evidence of proximal myopathy, Cushingoid striae, or other signs favoring Cushing syndrome. The basal (morning) 
TABLE 1: Investigation summary prior to the first surgery.

\begin{tabular}{|c|c|c|c|c|c|}
\hline Date & 20 and $21 / 6 / 2006$ & $11 / 8 / 2006$ & $17 / 1 / 2007$ & $16 / 7 / 2007$ & $28 / 11 / 2007$ \\
\hline S. cortisol, 8 am (mcg/dL) & 18.12 & 15.76 & \multirow{5}{*}{$\begin{array}{l}\text { Patient underwent } \\
\text { TSS and removal of } \\
\text { suspected pituitary } \\
\text { adenoma }\end{array}$} & \multirow{5}{*}{0.54} & \multirow{5}{*}{1.81} \\
\hline S. cortisol, 4 pm (mcg/dL) & 20.29 & & & & \\
\hline Overnight DST (1 mg) (mcg/dL) & 12.68 & & & & \\
\hline Low dose 48 hr DST ( 2 mg/day) (mcg/dL) & & 4.67 & & & \\
\hline High dose $48 \mathrm{hr}$ DST ( $8 \mathrm{mg} /$ day) (mcg/dL) & & 1.19 & & & \\
\hline
\end{tabular}

TABLE 2: Investigation summary-current evaluation.

\begin{tabular}{|c|c|c|c|c|c|c|}
\hline Date & Jan 2015 & $26 / 3 / 15$ & $27 / 3 / 15$ & $30 / 3 / 15 \& 4 / 4 / 15$ (supervised) & $4 / 4 / 15$ & $10 / 4 / 15$ \\
\hline S. cortisol $(8 \mathrm{am}) \mathrm{mcg} / \mathrm{dL}$ & 22.38 & & 9.63 & & 16.09 & \\
\hline S. cortisol (midnight) $\mathrm{mcg} / \mathrm{dL}$ & & & 4.95 & & 6.68 & \\
\hline Overnight DST $(1 \mathrm{mg}) \mathrm{mcg} / \mathrm{dL}$ & 13.20 & & & & & \\
\hline Low dose $48 \mathrm{hr}$ DST ( $2 \mathrm{mg} /$ day) $\mathrm{mcg} / \mathrm{dL}$ & 15.47 & Admitted & & 11.96 & & \\
\hline High dose $48 \mathrm{hr}$ DST ( $8 \mathrm{mg} /$ day) $\mathrm{mcg} / \mathrm{dL}$ & & Aumitted & & 6.39 & & \\
\hline Salivary cortisol midnight (normal [kit insert] $<0.42 \mathrm{mcg} / \mathrm{dL}$ ) & & & 0.306 & & 0.217 & \\
\hline $\mathrm{ACTH} \mathrm{pg} / \mathrm{mL}$ & & & 7.29 & & 29.85 & \\
\hline $24 \mathrm{Hr}$ urine free cortisol mcg/day (normal 28.5-213.7) & & & & & & 110.72 \\
\hline
\end{tabular}

cortisol was elevated, overnight (1 mg) dexamethasone suppression test and low dose $48 \mathrm{hr}$ ( $2 \mathrm{mg} /$ day) dexamethasone suppression test were both nonsuppressed, and the plasma ACTH level was also high [Table 2]. As she had a previous diagnosis of "Cushing disease," a recurrence was suspected and a dynamic contrast enhanced MRI of the sella was done which revealed a right sided delayed enhancing lesion on T1 weighted sequences suggestive of a pituitary microadenoma. The rest of the pituitary was normal on the MRI with a convex upper margin and the pituitary stalk central in position. She was admitted for a repeat transsphenoidal surgery for microadenoma, neurosurgical reference was taken, and it was planned for her to undergo surgery. On admission, as a routine, morning and midnight serum cortisol and midnight salivary cortisol tests and basal ACTH were evaluated which were normal and showed a preserved diurnal rhythm [Table 2]. This made our diagnosis suspicious. The surgery was put on hold, pending confirmation of the diagnosis.

Suspecting noncompliance to dexamethasone during testing, the low dose ( $2 \mathrm{mg}$ /day) DST was repeated under supervision in the ward, which was again unsuppressed. A high dose ( $8 \mathrm{mg} /$ day) DST was also done which showed $>50 \%$ reduction in the cortisol from baseline, but still the cortisol was above $5 \mathrm{mcg} / \mathrm{dL}$. A 24-hour urine free cortisol estimation was done which was normal [Table 2].

Intravenous dexamethasone suppression test was done to rule out hypercortisolism. The $4 \mathrm{mg}$-over-4-hour-infusion $(1 \mathrm{mg} / \mathrm{hr})$ protocol originally suggested by Abou-Samra et al. was used for the test [1]. Samples were drawn at $0 \mathrm{hr}, 4 \mathrm{hr}, 5 \mathrm{hr}$, and $24 \mathrm{hrs}$ of the starting of IV dexamethasone infusion. The expected response in a healthy person is $24 \mathrm{hr}$ (day 2) cortisol value of $<2.7 \mathrm{mcg} / \mathrm{dL}$ and in patients of Cushing syndrome is more than $>4.7 \mathrm{mcg} / \mathrm{L}$ (or $>20 \%$ of the baseline $[0 \mathrm{hr}]$ ) [2]. The dynamics of cortisol during the test are shown in Table 3 and Figure 1 which was normal. Hence, Cushing syndrome was ruled out. Now, an attempt to explain the false positive dexamethasone suppression test was made. Serum levels of dexamethasone could not be measured due to lack of resources. The patient was not on treatment with antiepileptic drugs, oral contraceptives, or any other medicines known to increase metabolism of dexamethasone. The patient did not have any clinical features of malabsorption and a $24 \mathrm{Hr}$ fecal fat excretion after fat loading of 75 grams/day was $0.51 \mathrm{~g} /$ day (normal: $<6$ grams/day). The patient was discharged with symptomatic measures for headache and advice on lifestyle modification for preventing weight gain.

\section{Discussion}

Although some authors have shown midnight serum cortisol to be highly sensitive and specific for the diagnosis of Cushing syndrome [3], the current clinical practice guidelines of the Endocrine Society suggest one of the four tests with high sensitivity ( $24 \mathrm{hr}$ urine free cortisol, midnight salivary cortisol, overnight (1 mg) DST, or low dose [2 mg/d] DST) should be used for the screening for Cushing syndrome [4]. If one of the above is positive, another of the remaining three should be done and if 2 of the four tests are positive this confirms the diagnosis of Cushing syndrome. Based on the guidelines Cushing syndrome was confirmed in the patient in the case report (unsuppressed overnight and low dose DST). MRI had also showed a lesion suggestive of microadenoma for which she underwent surgery previously and remained hypocortisolemic postoperatively probably due to surgical damage to the pituitary taking a long time to recover to normal. Additional tests in the wake of a normal diurnal rhythm of cortisol secretion made the diagnosis of Cushing syndrome unlikely and $4 \mathrm{mg}$ IV DST ruled it out decisively. Thus the oral dexamethasone suppression tests were false positive and the unnecessary surgery was 
TABLE 3: ACTH and cortisol dynamics during the intravenous dexamethasone suppression test.

\begin{tabular}{lcc}
\hline $4 \mathrm{mg}$ IV DST & S. cortisol & ACTH \\
\hline $0 \mathrm{hr}$ & $13.51 \mathrm{mcg} / \mathrm{dL}$ & $20.92 \mathrm{pg} / \mathrm{mL}$ \\
$4 \mathrm{hr}$ & $2.72 \mathrm{mcg} / \mathrm{dL}$ & $<1 \mathrm{pg} / \mathrm{mL}$ \\
$5 \mathrm{hr}$ & $2.05 \mathrm{mcg} / \mathrm{dL}$ & $<1 \mathrm{pg} / \mathrm{mL}$ \\
$24 \mathrm{hr}$ & $0.43 \mathrm{mcg} / \mathrm{dL}$ & $<1 \mathrm{pg} / \mathrm{mL}$ \\
\hline
\end{tabular}

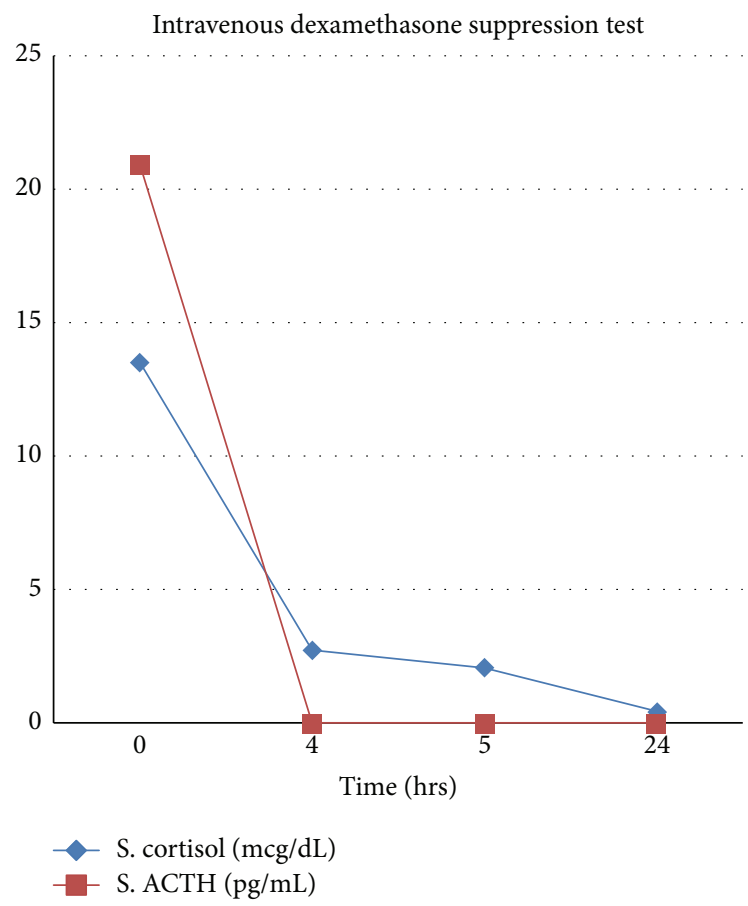

Figure 1: ACTH and cortisol dynamics during the intravenous dexamethasone suppression test.

averted. Presentations similar to the current case can be seen in patients with cyclical Cushing's syndrome and cortisol binding globulin (CBG) excess state. In this case, as oral DSTs and IV DST which were done at a gap of just 7 days showed a marked difference in supressibility cyclical Cushing was considered unlikely. Furthermore, as IVDST showed clearcut suppression of cortisol within hours of dexamethasone administration, CBG excess state was ruled out. IV DST is used in clinical situations where either decreased absorption of dexamethasone or its increased metabolism is suspected. It is reported that the plasma dexamethasone levels may vary widely in normal persons after oral administration for DSTs [5]. The rate of inactivation of dexamethasone by the human liver microsomes is highly variable as measured by the production of $6 \beta$-hydroxydexamethasone and other metabolites [6]. Simultaneous measurement of plasma dexamethasone levels and cortisol levels has been suggested to assess the adequacy of absorption of dexamethasone during DSTs, but this facility is not readily available outside the United States.

\section{Conclusion}

Through this report we point out why the diagnosis of Cushing syndrome must not be based on two oral dexamethasone suppression tests alone. A role of IV DSTs in cases where oral DSTs are contradictory to the other measures of hypercortisolism is emphasized by this case report. Before operating a case of Cushing syndrome with borderline features of hypercortisolism additional tests may be used for confirming or ruling out the diagnosis and the patient should be kept on follow-up till a definite diagnosis is reached.

\section{Additional Points}

Diagnosis of Cushing disease must not be based on oral dexamethasone suppression tests (DSTs) alone. Assessment of diurnal rhythm, salivary cortisol, and urine free cortisol levels can help in diagnosis. There is a definite role for intravenous DST in cases where oral DSTs are contradictory to other measures of hypercortisolism.

\section{Disclosure}

The work was carried out using interdepartmental collaboration.

\section{Competing Interests}

The authors declare that there are no competing interests regarding the publication of this paper.

\section{References}

[1] A. B. Abou Samra, H. Dechaud, B. Estour et al., " $\beta$-Lipotropin and cortisol responses to an intravenous infusion dexamethasone suppression test in Cushing's syndrome and obesity," Journal of Clinical Endocrinology and Metabolism, vol. 61, no. 1, pp. 116-119, 1985.

[2] C. Jung, F. P. Alford, D. J. Topliss et al., "The 4-mg intravenous dexamethasone suppression test in the diagnosis of Cushing's syndrome," Clinical Endocrinology, vol. 73, no. 1, pp. 78-84, 2010.

[3] D. L. Batista, J. Riar, M. Keil, and C. A. Stratakis, "Diagnostic tests for children who are referred for the investigation of Cushing syndrome," Pediatrics, vol. 120, no. 3, pp. e575-e586, 2007.

[4] L. K. Nieman, B. M. K. Biller, J. W. Findling et al., "The diagnosis of Cushing's syndrome: an endocrine society clinical practice guideline," The Journal of Clinical Endocrinology \& Metabolism, vol. 93, no. 5, pp. 1526-1540, 2008.

[5] A. W. Meikle, "Dexamethasone suppression tests: usefulness of simultaneous measurement of plasma cortisol and dexamethasone," Clinical Endocrinology, vol. 16, no. 4, pp. 401-408, 1982.

[6] D. M. Gentile, E. S. Tomlinson, J. L. Maggs, B. K. Park, and D. J. Back, "Dexamethasone metabolism by human liver in vitro. Metabolite identification and inhibition of 6-hydroxylation," Journal of Pharmacology and Experimental Therapeutics, vol. 277, no. 1, pp. 105-112, 1996. 


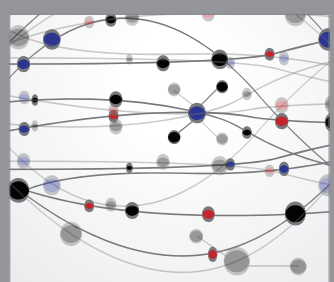

The Scientific World Journal
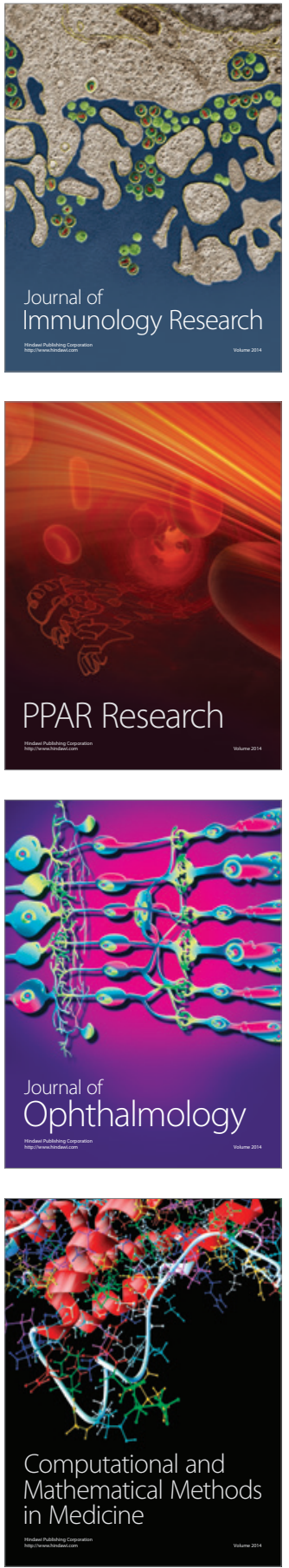

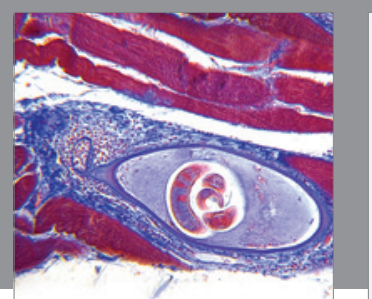

Gastroenterology Research and Practice

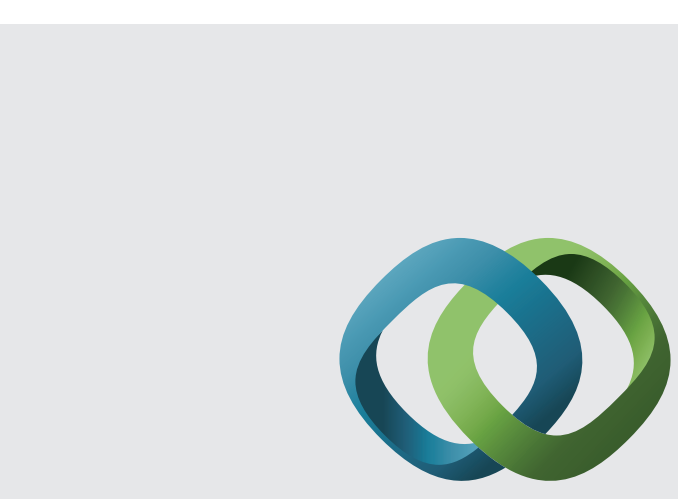

\section{Hindawi}

Submit your manuscripts at

http://www.hindawi.com
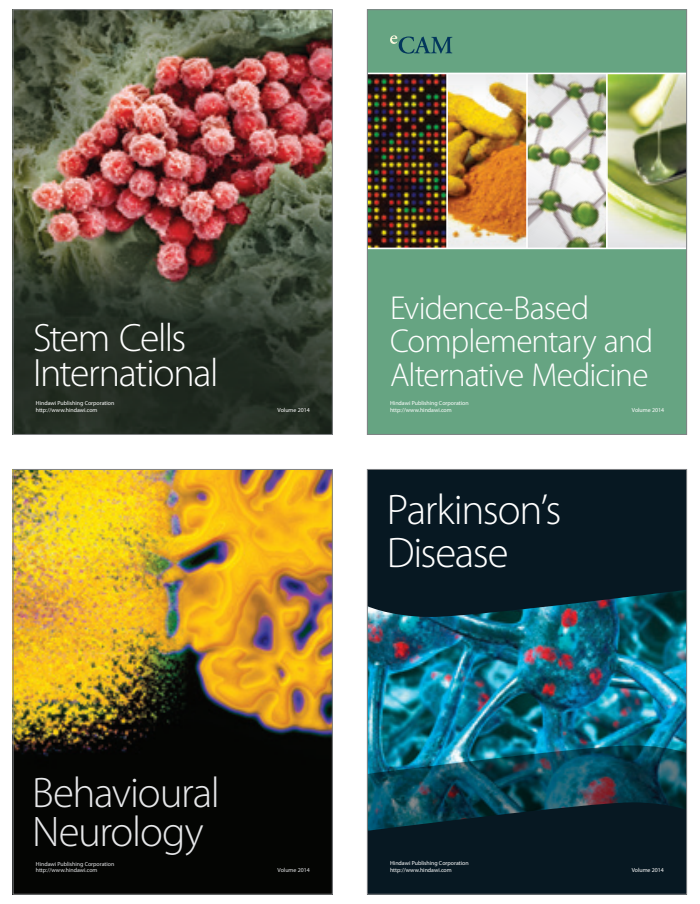
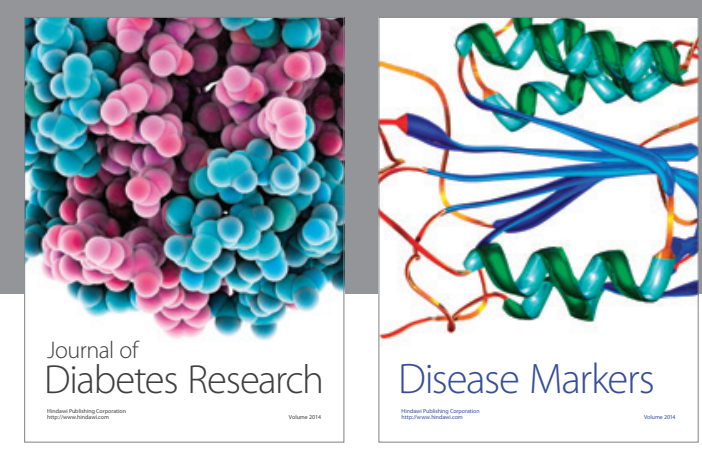

Disease Markers
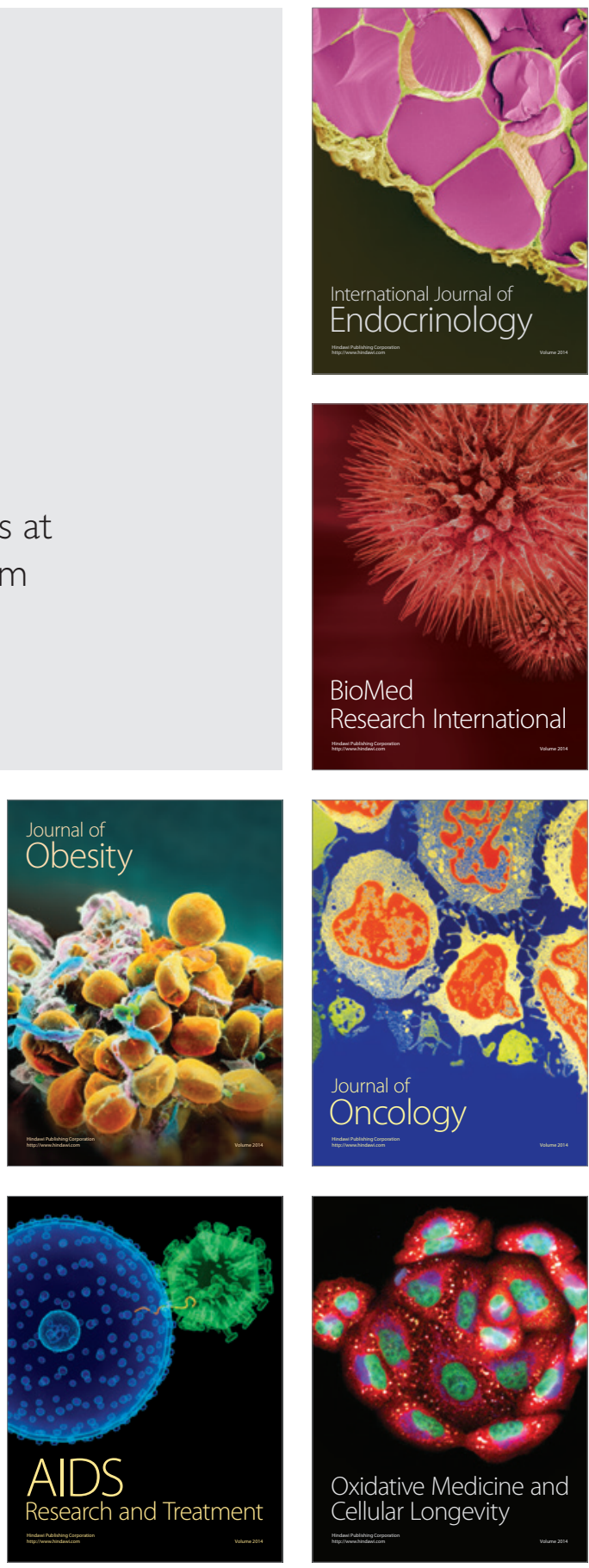